\title{
The Relationship between Dorsolateral Prefrontal Neuronal N-Acetylaspartate and Evoked Release of Striatal Dopamine in Schizophrenia
}

\author{
Alessandro Bertolino, M.D., Alan Breier, M.D., Joseph H. Callicott, M.D., Caleb Adler, M.D., \\ Venkata S. Mattay, M.D., Maxim Shapiro, B.S., Joseph A. Frank, M.D., \\ David Pickar, M.D., and Daniel R. Weinberger, M.D.
}

Schizophrenia has been linked to abnormal dopamine function, recently to excessive amphetamine-induced release of striatal dopamine, and also to pathology of prefrontal cortical neurons. It has been hypothesized that prefrontal pathology is a primary condition that leads to dopamine dysregulation. We evaluated in vivo the relationship between neuronal integrity in dorsolateral prefrontal cortex, assessed as N-acetylaspartate (NAA) relative concentrations measured with proton magnetic resonance spectroscopic imaging, and amphetamineinduced release of striatal dopamine, assessed with ${ }^{11} \mathrm{C}$ raclopride Positron Emission Tomography (PET) in patients with schizophrenia and in healthy subjects. In the patients, NAA measures in dorsolateral prefrontal cortex selectively predicted striatal displacement of ${ }^{11} \mathrm{C}$-raclopride after amphetamine infusions (rho $=-0.76, \mathrm{p}<.02$ ). In contrast, NAA measures in other cortical regions and in healthy subjects did not show any correlation. These results support the hypothesis that in schizophrenia neuronal pathology of dorsolateral prefrontal cortex is directly related to abnormal subcortical dopamine function.

[Neuropsychopharmacology 22:125-132, 2000]

Published by Elsevier Science Inc.
KEY WORDS: Dorsolateral prefrontal cortex;

N-acetylaspartate; Striatum; Dopamine; Evoked release;

Schizophrenia

Considerable evidence has emerged over the years implicating the dopaminergic system in the pathophysiol-

From the Clinical Brain Disorders Branch, Intramural Research Programs (AB, JHC, VSM, MS, DRW) and Experimental Therapeutics Branch (ABr, CA, DP), National Institute of Mental Health, and the Laboratory of Diagnostic Radiology Research (JAF), OD, NIH, Bethesda, MD.

Address correspondence to: Daniel R. Weinberger, M.D., Clinical Brain Disorders Branch, Intramural Research Programs, National Institute of Mental Health, NIH, 10 Center Drive Room 4S235 MSC 1379, Bethesda, MD 20892.

Received March 11, 1999; revised July 27, 1999; accepted August 2, 1999. ogy of schizophrenia. The "dopaminergic hypothesis" of schizophrenia, that suggested hyperactivity of central dopamine neurons, was based on indirect pharmacological evidence (Carlsson 1988); for example, dopamimetic drugs such as amphetamine have psychotogenic properties and antipsychotic drugs, such as chlorpromazine, are dopamine antagonists.

Efforts to measure directly dopamine concentrations, metabolic enzymes, and receptor protein abundance in post mortem tissue and dopamine receptor binding with in vivo neuroimaging techniques have been largely inconclusive, dimming enthusiasm for the traditional dopamine hypothesis (Hietala et al. 1994; Kornhuber et al. 1989; Lee et al. 1978; Knable et al. 1997). However, three recent studies using D2 radioreceptor 
imaging have found that amphetamine causes larger displacement of the ligand from striatal receptors in schizophrenic than in healthy subjects, suggesting greater release of dopamine following amphetamine challenges (Laruelle et al. 1996; Abi-Dargham et al. 1998; Breier et al. 1997). These data have reinvigorated interest in a dopamine abnormality, not in terms of "too much dopamine" per se, but in more subtle terms of abnormal responses of dopamine neurons to stimuli.

An independent line of neuropathological evidence has emerged over the past decade, based on neuroimaging, neuropsychological, as well as post mortem tissue studies, implicating the dorsolateral prefrontal cortex as a site of neuronal involvement in schizophrenia (Goldman-Rakic 1987; Weinberger et al. 1986; Pettigrew et al. 1991). Consequently, it has been suggested that dopamine system dysregulation in schizophrenia might be a result of pathology of dorsolateral prefrontal cortex (Weinberger 1987; Deutch 1992; Davis et al. 1991; Grace 1991). The latter hypothesis was based primarily on evidence from experiments in rodents, which have indicated that the prefrontal cortex through glutamatergic projections (Divac et al. 1978) regulates the burst firing patterns (Svensson and Tung 1989; Murase et al. 1993) and the number of spontaneously active dopamine neurons in the ventral brainstem (Shim et al. 1996). Moreover, it has been demonstrated that prefrontal lesions exaggerate the release of subcortical dopamine evoked by drug challenges (including amphetamine) as well as by stress (Braun et al. 1993; Jaskiw et al. 1990; Flores et al. 1996; Roberts et al. 1994). Consistent with this evidence, in a previous study in monkeys with developmental pathology of dorsolateral prefrontal cortex, we found that in vivo measures of neuronal integrity in dorsolateral prefrontal cortex inversely predict release of dopamine after amphetamine infusions (Bertolino et al. 1999).

The purpose of the present study was to assess the in vivo relationship between a measure of neuronal integrity in dorsolateral prefrontal cortex and amphetamineinduced release of striatal dopamine in patients with schizophrenia and in healthy subjects. Based on animal literature and on our previous study in monkeys, we hypothesized that our measure of neuronal integrity of dorsolateral prefrontal cortex would predict greater amphetamine-induced striatal release of dopamine in patients with schizophrenia. We used proton magnetic resonance spectroscopic imaging $\left({ }^{1} \mathrm{H}-\mathrm{MRSI}\right)$ and ${ }^{11} \mathrm{C}$-raclopride Positron Emission Tomography (PET) in each subject. The former technique allows in vivo measurement and mapping of N-acetyl-containing compounds, mainly N-acetylaspartate (NAA), cholinecontaining compounds $(\mathrm{CHO})$, and creatine + phosphocreatine (CRE). NAA is an intraneuronal amino acid with highest concentrations in pyramidal glutamatergic neurons (Moffett and Namboodiri 1995).
Several earlier studies have demonstrated reduced NAA measures in the prefrontal cortex and in mesial temporal lobes of patients with schizophrenia (Deicken et al. 1998; Callicott et al. 1998; Bertolino et al. 1996, 1998a; Buckley et al. 1994; Maier et al. 1995; Nasrallah et al. 1994; Renshaw et al. 1995; but also Stanley et al. 1996) consistent with post mortem evidence of compromised neuronal integrity in these regions (Selemon et al. 1995; Weinberger 1999).

We used ${ }^{11} \mathrm{C}$-raclopride PET to assess amphetamineevoked release of dopamine in the striatum. ${ }^{11} \mathrm{C}$-raclopride has high selectivity and low affinity for dopamine D2/D3 receptors and competes with synaptic dopamine for receptor occupancy (Breier et al. 1997). Therefore, by measuring in the same experiment both baseline raclopride binding and the change caused by amphetamine infusions, it is possible to indirectly measure amphetamine-induced release of dopamine (Breier et al. 1997).

\section{METHODS}

\section{Subjects}

Nine patients (6 males and 3 females, age mean \pm S.D. $=40.1 \pm 8.7$ years) who met DSM-IV criteria for schizophrenia and had been chronically ill (illness duration $=16.2 \pm 10.7$ years) gave informed consent and volunteered to participate in this study. Diagnoses based on DSM-IV criteria were determined by a diagnostic conference utilizing data from a structured diagnostic interview (SCID), clinical interview by a research psychiatrist, past psychiatric and medical records, and informant interviews. Four of the nine patients had no prior antipsychotic drug exposure. The remaining five patients had been free of antipsychotic drug treatment for at least two weeks prior to both studies (mean $18 \pm$ 3.4 days, range $15-23$ days).

Exclusion criteria included history of significant drug abuse, head trauma with loss of consciousness, and any medical condition that made amphetamine administration contraindicated. The PET data for six of the patients have been previously reported (Breier et al. 1997) and the ${ }^{1} \mathrm{H}-\mathrm{MRSI}$ data of four of the patients have been reported in another publication (Bertolino et al. 1998a). Seven healthy subjects of similar age (5 males, age $36.4 \pm 7.3)$ were also studied. The Brief Psychiatric Rating Scale (BPRS) was administered to all subjects at baseline, 15 and 70 minutes after the infusion of amphetamine.

\section{${ }^{1} \mathrm{H}$-MRSI Procedure}

${ }^{1} \mathrm{H}$-MRSI was performed on a GE-SIGNA 1.5 Tesla MR scanner (GE Medical Systems, Milwaukee, WI) as in earlier reports (Bertolino et al. 1996, 1998a, 1998b; Duyn 
et al. 1993). Briefly, the ${ }^{1} \mathrm{H}-\mathrm{MRSI}$ sequence involves a spin echo slice selection with repetition time (TR) of $2200 \mathrm{~ms}$ and echo time (TE) of $272 \mathrm{~ms}$ and includes suppression of water and most of the signal arising from lipids in the skull marrow and in surface tissues (outer volume saturation) (Duyn et al. 1993). Phase encoding procedures were used to obtain a $32 \times 32$ array of spectra from volume elements in each selected slice. Each volume element ("voxel") had nominal dimensions of $7.5 \times 7.5 \times 15 \mathrm{~mm}(0.84 \mathrm{~mL})$. Actual volume, based on full width at half maximum (FWHM) after filtering of k-space, was $1.4 \mathrm{~mL}$ (Duyn et al. 1993). The filter was a radial cosine filter starting at half-maximum radius.

To produce metabolite maps, location and integration of the signal strength (range $0.2 \mathrm{ppm} ; 0.1 \mathrm{ppm}$ on each side of the center of the peak) of NAA, CHO, and CRE peaks in all brain voxels was automatically computed. Metabolite signals are reported as ratios of the area under the peaks NAA/CRE, NAA/CHO, and $\mathrm{CHO} / \mathrm{CRE}$. Regions of interest (ROIs) were drawn blindly with reference to standard anatomical atlases by two raters on coplanar structural MRI scans (ICC for the two raters $=0.92$ ). The method for drawing the ROIs is described in detail elsewhere (Bertolino et al. 1996). These ROIs were then transferred by computer on the ${ }^{1} \mathrm{H}-\mathrm{MRSI}$ maps and the average NAA, CHO, and CRE values were computed. ROIs were identified in dorsolateral prefrontal cortex, hippocampal area, and in other cortical regions that served as comparison regions. These regions included superior temporal gyrus, inferior frontal gyrus, occipital cortex, and anterior and posterior cingulate.

\section{${ }^{11}$ C-raclopride PET Procedure}

All scans were performed as previously reported (Breier et al. 1997). Briefly, a GE Advance scanner was used to obtain 35 planes (4.25 mm gap) with an effective resolution after reconstruction of $6 \mathrm{~mm}$ isotropic. A transmission scan was performed using two rotating ${ }^{68} \mathrm{Ge}$ sources for attenuation correction. Subjects were oriented in the scanner such that scanning planes would be parallel to the orbito-meatal line. ${ }^{11} \mathrm{C}$-raclopride $(2-8 \mathrm{mCi})$ was administered as a bolus followed by a constant infusion over $2 \mathrm{hr}$. The bolus was $53 \%$ of the total amount administered. Twenty-nine scans were acquired over the $2 \mathrm{hr}$. period; one every 3-5 min. Fifty minutes after beginning the raclopride administration, amphetamine $(0.2 \mathrm{mg} / \mathrm{kg}$, i.v. $)$ was infused over a period of $60 \mathrm{sec}$. Pulse rate and blood pressure were measured throughout the scans.

Image processing was performed with proprietary software ("MIRAGE") developed by the NIH PET center. The images corresponding to $0-5 \mathrm{~min}$ of raclopride infusion were added together to form a single sum image. Volumes of interest (VOIs) were drawn in the cere- bellum and on the left and right striatum (caudate and putamen together). These VOIs were then overlaid onto their corresponding position in each of the 35 individual scans, and samples (mean pixel values) were generated for each VOI. Left and right striatal VOIs were averaged to a single striatal value. These data obtained from five consecutive scans $30-50 \mathrm{~min}$ after injection and immediately before amphetamine administration (baseline) and five consecutive scans 75-100 min post raclopride bolus injection (postamphetamine) were averaged. Left and right striatal ROIs were also averaged. The specific raclopride binding was expressed as a ratio striatum/cerebellum. Spearman analyses were performed between ${ }^{1} \mathrm{H}$-MRSI ratios and striatal percent change in specific raclopride binding.

\section{RESULTS}

Amphetamine did not cause any significant change in pulse (mean of healthy subjects, before and after: 58 and 60; mean of patients with schizophrenia, before and after: 63 and 70) or in systolic blood pressure (mean of healthy subjects, before and after: $148 \mathrm{mmHg}$ and 148 $\mathrm{mmHg}$; mean of patients with schizophrenia, before and after: $160 \mathrm{mmHg}$ and $153 \mathrm{mmHg}$ ). Fifteen minutes after the infusion of amphetamine there was a temporary and slight increase in BPRS total score in the patients and in healthy subjects (mean BPRS total score, before and after in patients and controls: 38 and 42; 24 and 29, respectively). At 70 minutes, however, these increases had receded to baseline levels both in patients and controls (mean in patients and controls: 38 and 24, respectively). No untoward clinical effects were observed in patients upon their return to the ward after the conclusion of the PET procedure.

The cerebellar ROI was not available for one patient and, therefore, the results are presented for eight patients. In this small sample of subjects, the patients as a group did not differ significantly from healthy subjects in terms of mean NAA/CRE in dorsolateral prefrontal cortex (mean \pm SD for healthy subjects and patients with schizophrenia: $2.67 \pm 0.19$ and $2.59 \pm 0.21$, respectively). However, the patients showed significantly higher displacement of raclopride after infusion of amphetamine (mean in patients: 26.7; mean in controls: 15.7; $t=2.1, d f=14, p<.03)$.

In the patients with schizophrenia, dorsolateral prefrontal cortex NAA/CRE correlated with percent change in raclopride binding in the striatum after amphetamine infusions $(n=8, r h o=-0.76, p<.02$ (Figure 1). Lower NAA/CRE in dorsolateral prefrontal cortex predicted higher changes in raclopride binding. To assess whether the correlation was attributable to NAA measures, we also examined the relationship between $\mathrm{NAA} / \mathrm{CHO}$ and $\mathrm{CHO} / \mathrm{CRE}$ in dorsolateral prefrontal 
cortex and change in raclopride binding in the striatum. While NAA/CHO showed a significant correlation, $\mathrm{CHO} / \mathrm{CRE}$ did not $[$ rho $=-0.69, p<.05$ (Figure 2) and $r h o=0.04, p>.9$ (Figure 3), respectively] supporting the contention that the relationship is specific to NAA measures. No other cortical region showed any significant correlation even at the trend level after an appropriate Bonferroni correction for the number of comparisons.

In healthy subjects, NAA/CRE in dorsolateral prefrontal cortex was not predictive of change in raclopride binding ( $r h o=0.10, p>.7$ ). Thus, this relationship appears specific to schizophrenia.

\section{DISCUSSION}

The purpose of the present study was to investigate the relationship between NAA measures in a population of neurons in dorsolateral prefrontal cortex and amphetamine-induced release of dopamine in patients with schizophrenia and in healthy subjects. We found a selective negative correlation between NAA measures in dorsolateral prefrontal cortex and changes in striatal raclopride binding after amphetamine infusion in patients with schizophrenia. Lower NAA measures in dorsolateral prefrontal cortex predicted greater decrease in raclopride binding, likely caused by increased amphetamine-induced release of dopamine. No other region in the patients or NAA measures in dorsolateral prefrontal cortex of healthy subjects show this correlation, underlining the regional specificity of this relationship and its association with schizophrenia. Therefore, the present data demonstrate that the apparent increased release of striatal dopamine after amphetamine infusions in patients with schizophrenia is related to NAA measures in dorsolateral prefrontal cortex. These data are also consistent with the results of our previous study in non-human primates with developmental pathology of dorsolateral prefrontal cortex wherein we showed that NAA measures in dorsolateral prefrontal cortex inversely predicted release of striatal dopamine after infusion of amphetamine into dorsolateral prefrontal cortex (Bertolino et al. 1999).

The interpretation of the NAA component of this relationship is uncertain. While NAA is found in all neurons (Urenjak et al. 1993), its concentration is highest in pyramidal glutamatergic neurons (Moffett and Namboodiri 1995). NAA synthesis in the mitochondria is ADP dependent, catalyzed by L-aspartate- $\mathrm{N}$-acetyl transferase that uses glutamate as a precursor for aspartate and either pyruvate or 3-hydroxybutyrate (source of Acetyl CoA) as substrates (Clark 1998).

While the biological role of NAA has yet to be clearly defined, it acts via the glutamatergic NMDA receptor to elevate intracellular calcium (Rubin et al. 1995), and its concentrations are reduced by pharmacological inhibi- tion of mitochondrial energy metabolism (Bates et al. 1996) as well as by a number of pathological processes affecting the integrity of neurons (Cendes et al. 1997; De Stefano et al. 1995; Najim et al. 1998). Other data also suggest that NAA concentrations vary with the structural and functional state of glutamatergic cells. For example, NAA increases during pharmacologically induced status epilepticus and then decreases after neuronal damage has occurred (Najim et al. 1998). Surgical removal of the epileptic focus in temporal lobe epilepsy reverses NAA decreases not only in the affected side but also in the contralateral side, presumably by modulating abnormal interhemispheric glutamatergic projections (Cendes et al. 1997).

We have previously shown that NAA levels are reduced in patients with schizophrenia in the hippocampal area and the dorsolateral prefrontal cortex, two areas in which glutamatergic pathology has been implicated in schizophrenia (Akbarian et al. 1996; Eastwood et al. 1995). Moreover, we have shown that NAA levels in dorsolateral prefrontal cortex of patients with schizophrenia predict activation of the entire working memory related cortical network, including prefrontal cortex, parietal cortex, and cingulate, consistent with the excitatory role of glutamatergic neurons projecting from dorsolateral prefrontal cortex to these other brain regions (Bertolino et al. 1997).

Taken together, these various data suggest that NAA measures, at least in the context of neuronal pathology, may vary as a correlate of glutamatergic activity of neurons. This speculation is consistent with another body of research indicating that glutamatergic projections from prefrontal cortex in rodents (Svensson and Tung 1989; Murase et al. 1993; Shim et al. 1996) and primates (Saunders et al. 1998) regulate activity of ventral brainstem dopaminergic neurons and striatal release of dopamine. Lesions of the prefrontal cortex enhance the responsiveness of the mesencephalic dopamine system to pharmacological challenges that activate the dopaminergic system (Jaskiw et al. 1990; Roberts et al. 1994), including behavioral responses to dopamine agonists such as amphetamine and apomorphine (Braun et al. 1993; Jaskiw et al. 1990; Flores et al. 1996; Roberts et al. 1994). The present study represents the first attempt to correlate an in vivo neuronal measure in dorsolateral prefrontal cortex and evoked release of striatal dopamine in human subjects, and the results are consistent with the above mentioned experiments in animals. The present data are also consistent with the hypothesis that dopamine dysregulation in schizophrenia may be prefrontally determined. Healthy subjects, on the other hand, do not show this relationship, presumably because it reflects abnormal function of dorsolateral prefrontal cortex projecting neurons.

There is an alternative explanation of our data that should be mentioned. Amphetamine, in addition to 

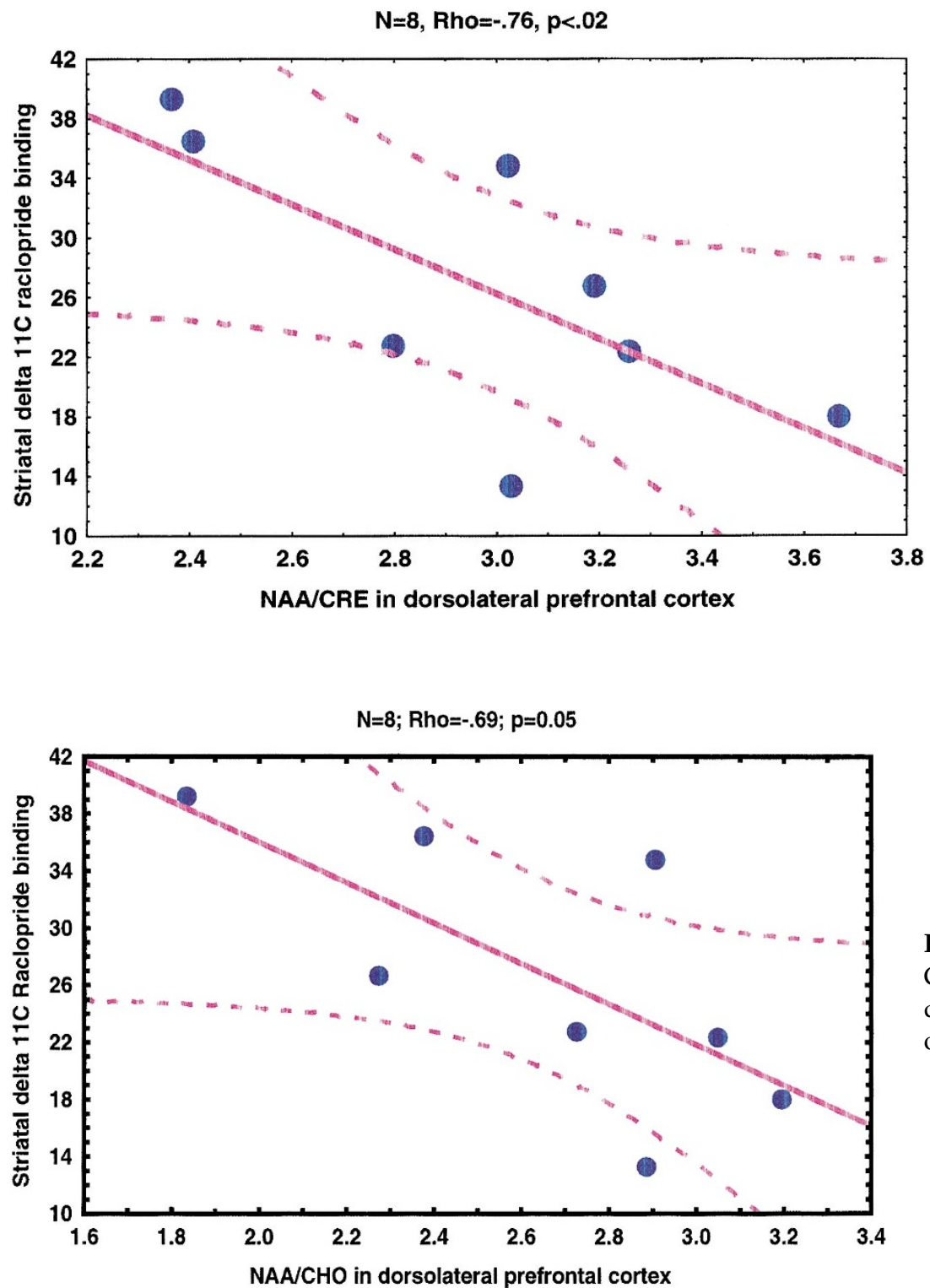

$\mathrm{N}=8 ; \mathrm{Rho}=.04 ; \mathrm{p}=\mathrm{n} . \mathrm{s}$

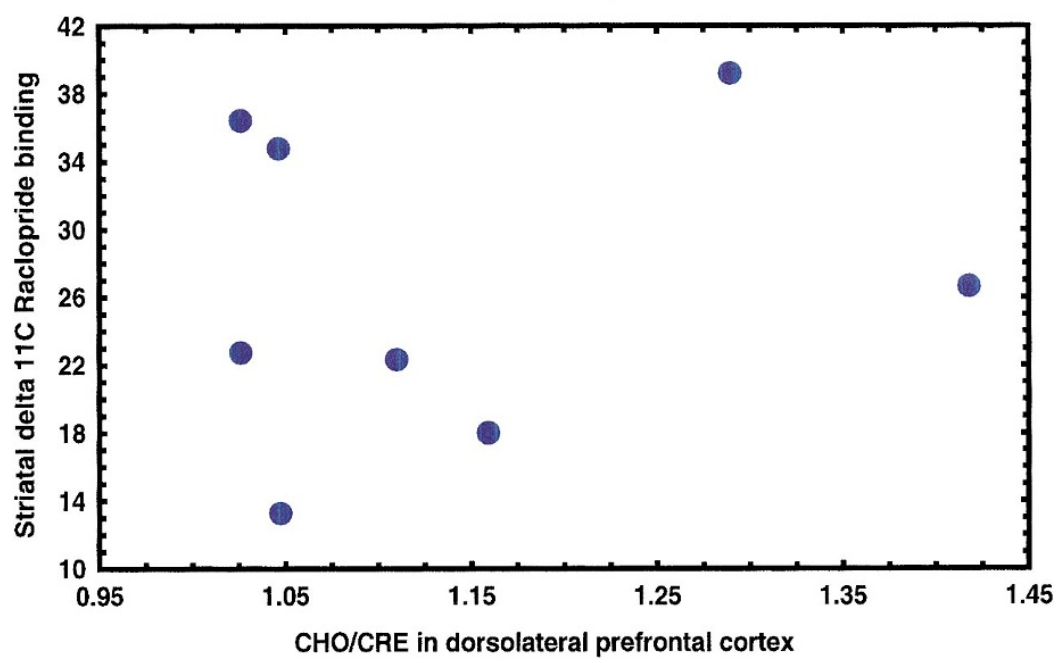

Figure 1. The relationship between NAA/CRE in dorsolateral prefrontal cortex and change (delta) in ${ }^{11} \mathrm{C}$-raclopride (before and after systemic infusions of amphetamine) binding in the striatum of patients with schizophrenia.
Figure 2. The relationship between NAA/ $\mathrm{CHO}$ in dorsolateral prefrontal cortex and delta ${ }^{11} \mathrm{C}$-raclopride binding in the striatum of patients with schizophrenia.

Figure 3. The relationship between $\mathrm{CHO} /$ CRE in dorsolateral prefrontal cortex and delta ${ }^{11} \mathrm{C}$-raclopride binding in the striatum of patients with schizophrenia. 
causing release of dopamine and other biogenic amines, also causes release of glutamate (Del Arco et al. 1998). Therefore, it is conceivable that NAA measures in neurons of dorsolateral prefrontal cortex correlate with striatal amphetamine-induced release of dopamine simply because they predict the potential of these neurons in dorsolateral prefrontal cortex to release glutamate after amphetamine infusions, both neurotransmitter release phenomena being linked to amphetamine. However, if this were the explanation for our findings, it is not likely that the correlation would have been so regionally specific.

In this small sample of subjects, the groups did not differ in terms of NAA measures in dorsolateral prefrontal cortex. This is not surprising based on the effect size of the NAA reductions found in earlier studies, which indicate that a group of $n=64-80$ is required to avoid type II error (power $>70-80 \%, b<0.2-0.3$ ) (Callicott et al. 1998). This effect size reflects both the subtlety of the NAA deviation as well as the error in the measurement. However, it is important to underline that this study was not performed to assess mean NAA differences or differences in displacement of raclopride after amphetamine in schizophrenia. The differences in NAA measures between patients and healthy subjects have been repeatedly found in a series of studies from different groups of investigators in larger samples, indicating that, in schizophrenia, NAA values are generally shifted downward presumably indicative of compromised neuronal integrity (Deicken et al. 1998; Callicott et al. 1998; Bertolino et al. 1996, 1998a; Buckley et al. 1994; Maier et al. 1995; Nasrallah et al. 1994; Renshaw et al. 1995; but also Stanley et al. 1996). Instead, the purpose of the present study was to explore the correlation between these measures, which we have demonstrated.

Prior treatment with neuroleptics is always a potential confound in studies of patients with schizophrenia, even if medication-free at the time of the study. In the present paper, we report a correlation between prefrontal NAA and the amphetamine-induced displacement of raclopride. We believe that the regionally specific nature of the NAA variable is difficult to attribute to a medication effect, and the displacement measure is intrinsically less prone to possible effects of previous treatment with neuroleptics as this represents the difference within a subject between baseline and afteramphetamine binding of raclopride measured in the same session. Nevertheless, we cannot categorically exclude a role of past neuroleptic treatment on the emergence of the correlations within the patient group.

In conclusion, the results of this study in patients with schizophrenia show a selective correlation between a measure of prefrontal neuronal integrity and amphetamine-induced striatal release of dopamine in that lower indices of prefrontal neuronal integrity are predictive of higher striatal release of dopamine. These results lend further evidence to the proposal that it may be possible to ameliorate dopamine related clinical aspects of schizophrenia at the level of dorsolateral prefrontal cortex glutamatergic function (Weinberger 1987; Moghaddam and Adams 1998).

\section{REFERENCES}

Abi-Dargham A, Gil R, Krystal J, Baldwin RM, Seibyl JP, Bowers $\mathrm{M}$, Van Dyck CH, Charney DS, Innis RB, Laruelle M (1998): Increased striatal dopamine transmission in schizophrenia: Confirmation in a second cohort. Am J Psychiatry 155:761-767

Akbarian S, Sucher NJ, Bradley D, Taffazzoli A, Trinh D, Hetrick WP, Potkin SG, Sandman CA, Bunney WE, Jones EG (1996): Selective alterations in gene expression for NMDA receptor subunits in prefrontal cortex of schizophrenics. J Neurosci 16:19-30

Bates TE, Stranward M, Keelan J, Davey GP, Munro PMG, Clark JB (1996): Inhibition of N-acetylaspartate production: Implications for $1 \mathrm{H}$ MRS studies. Neuroreport 7:1397-1400

Bertolino A, Callicott JH, Elman I, Mattay VS, Tedeschi G, Frank JA, Breier A, Weinberger DR (1998a): Regionally specific neuronal pathology in untreated patients with schizophrenia: A proton magnetic resonance spectroscopic imaging study. Biol Psychiatry 43:641-648

Bertolino A, Callicott JH, Nawroz S, Mattay VS, Duyn JH, Tedeschi G, Frank JA, Weinberger DR (1998b): Reproducibility of proton magnetic resonance spectroscopic imaging in patients with schizophrenia. Neuropsychopharmacology 18:1-9

Bertolino A, Esposito G, Callicott JH, Mattay VS, vVan Horn JD, Frank JA, Berman KF, Weinberger DR (1997): 1HMRSI correlates with rCBF activation during working memory in patients with schizophrenia. Neuroimage $5: 281$

Bertolino A, Knable MB, Saunders RC, Callicott JH, Kolachana BS, Mattay VS, Bachevalier J, Egan MF, Frank JA, Weinberger DR (1999): The relationship between dorsolateral prefrontal N-acetylaspartate measures and striatal dopamine activity in schizophrenia. Biol Psychiatry 45:660-667

Bertolino A Nawroz S, Mattay VS, Duyn JH, Moonen CTW, Barnett AS, Frank JA, Tedeschi G, Weinberger DR (1996): A specific pattern of neurochemical pathology in schizophrenia as assessed by multislice proton magnetic resonance spectroscopic imaging. Am J Psychiatry 153:1554-1563

Braun AR, Jaskiw GE, Vladar K, Sexton RH, Kolachana BS, Weinberger DR (1993): Effects of ibotenic acid lesion of the medial prefrontal cortex on dopamine agonistrelated behaviors in the rat. Pharm Biochem Behav 46:51-60

Breier A, Su TP, Saunders R, Carson RE, Kolachana BS, De Bartolomeis A, Weinberger DR, Weisenfeld N, Malhotra AK, Eckelman WC, Pickar D (1997): Schizophrenia is associated with elevated amphetamine-induced synaptic dopamine concentrations: Evidence from a novel positron emission tomography method. Proc Natl Acad Sci USA 94:2569-2574 
Buckley PF, Moore C, Long H, Larkin C, Thompson P, Mulvany $\mathrm{F}$, Redmond $\mathrm{O}$, Stack JP, Ennis JT, Waddington JL (1994): 1H Magnetic resonance spectroscopy of the left temporal and frontal lobes in schizophrenia: Clinical neurodevelopmental and cognitive correlates. Biol Psychiatry 36:792-800

Callicott JH, Eegan MF, Bertolino A, Mattay VS, Langheim FJP, Frank JA, Weinberger DR (1998): Hippocampal $\mathrm{N}$-acetylaspartate in unaffected siblings of patients with schizophrenia: A possible intermediate phenotype. Biol Psychiatry 44:941-950

Carlsson A (1988): The current status of the dopamine hypothesis of schizophrenia. Neuropsychopharmacology 1:179-186

Cendes F, Andermann F, Dubeau F, Matthews PM, Arnold DL (1997): Normalization of neuronal metabolic dysfunction after surgery for temporal lobe epilepsy. Evidence from proton MR spectroscopic imaging. Neurology 49:1525-1533

Clark JB (1998): N-acetyl aspartate: A marker for neuronal loss or mitochondrial dysfunction. Dev Neurosci 20:271-276

Davis KL, Kahn RS, Ko G, Davidson M (1991): Dopamine in schizophrenia: A review and reconceptualization Am J Psychiatry 148:1474-1486

Deicken RF, Zhou L, Schuff N, Fein G, Weiner MW (1998): Hippocampal neuronal dysfunction in schizophrenia as measured by proton magnetic resonance spectroscopy. Biol Psychiatry 43:483-488

Del Arco A, Martinez R, Mora F (1998): Amphetamine increases extracellular concentrations of glutamate in the prefrontal cortex of the awake rat: A microdialysis study. Neurochem Res 23:1153-1158

De Stefano N, Matthews P, Antel JP, Preul M, Francis G, Arnold DL (1995): Chemical pathology of acute demyelinating lesions and its correlations with disability. Ann Neurol 38:901-909

Deutch AY (1992): The regulation of subcortical dopamine systems by the prefrontal cortex: Interactions of central dopamine systems and the pathogenesis of schizophrenia. J Neural Transm Suppl 36:61-89

Divac I, Kosmal A, Bjorklund A, Lindvall O (1978): Subcortical projections to the prefrontal cortex in the rat as revealed by the horseradish peroxidase technique. Neuroscience 3:785-796

Duyn JH, Gillen J, Sobering G, van Zijl PC, Moonen CTW (1993): Multisection proton MR spectroscopic imaging of the brain. Radiology 188:277-282

Eastwood SL, McDonald B, Burnet PW, Beckwith JP, Kerwin RW, Harrison PJ (1995): Decreased expression of mRNAs encoding non-NMDA glutamate receptors GluR1 and GluR2 in medial temporal lobe neurons in schizophrenia. Mol Brain Res 29:211-223

Flores G, Wood GK, Liang JJ, Quirion R, Srivastava LK (1996): Enhanced amphetamine sensitivity and increased expression of dopamine D2 receptors in postpubertal rats after neonatal excitotoxic lesions of the medial prefrontal cortex. J Neurosci 16:7366-7375

Goldman-Rakic PS (1987): Handbook of Physiology: The Nervous System. Bethesda, MD, American Physiological Society, pp 373-417
Grace AA (1991): Phasic versus tonic dopamine release and the modulation of dopamine system responsivity: A hypothesis for the etiology of schizophrenia. Neuroscience 41:1-24

Hietala J, Syvalahti E, Vuorio K (1994): Striatal dopamine D2 receptor binding characteristics in neuroleptic naive schizophrenics studied with positron emission tomography. Arch Gen Psychiatry 51:116-123

Jaskiw GE, Karoum FK, Weinberger DR (1990): Persistent elevations in dopamine and its metabolites in the nucleus accumbens after mild subchronic stress in rats with ibotenic acid lesions of the medial prefrontal cortex. Brain Res 534:321-323

Knable MB, Egan MF, Heinz A, Gorey J, Lee KS, Coppola R, Weinberger DR (1997): Evidence for a relationship between altered dopaminergic function and negative symptoms in drug-free schizophrenic patients: An I-123 IBZM-SPECT study. Br J Psychiatry 171:574-577

Kornhuber J, Riederer P, Reynolds GP, Beckmann H, Jellinger K, Gabriel E (1989): 3H-spiperone binding sites in post-mortem brains from schizophrenic patients: Relationship to neuroleptic drug treatment, abnormal movements, and positive symptoms. J Neural Transm 75:1-10

Laruelle M, Abi-Dargham A, van-Dyck CH, Gil R, D'Souza CD, Erdos J, McKCance E, Rosenblatt W, Fingado C, Zoghbi SS, Baldwin RM, Seibyl JP, Krystal JH, Charney DS, Innis, RB (1996): Single-photon emission computerized tomography imaging of amphetamine-induced dopamine release in drug-free schizophrenic subjects. Proc Natl Acad Sci 93:9235-9240

Lee T, Seeman P, Toutellotte WW, Farley IJ, Hornykiewicz O (1978): Binding of 3H-neuroleptics and 3H-apomorphine in schizophrenic brains. Nature 274:897-900

Maier M, Ron MA, Barker GJ, Tofts PS (1995): Proton magnetic resonance spectroscopy: An in vivo method of estimating hippocampal neuronal depletion in schizophrenia. Psychol Med 25:1201-1209

Moffett JR, Namboodiri MA (1995): Differential distribution of N-acetylaspartylglutamate and N-acetylaspartate immunoreactivities in rat forebrain. J Neurocytol 24: 409-433

Moghaddam B, Adams BW (1998): Reversal of phencyclidine effects by a group II metabotropic glutamate receptor agonist in rats. Science 281:1349-1352

Murase S, Grenhoff J, Chouvet G, Gonon FG, Svensson TH (1993): Prefrontal cortex regulates burst firing and transmitter release in rat mesolimbic dopamine neurons studied in vivo. Neurosci Lett 157:53-56

Najim IM, Wang Y, Shedid D, Luders HO, Ng TC, Comair YG (1998): MRS metabolic markers of seizures and seizure-induced neuronal damage. Epilepsia 39:244-250

Nasrallah HA, Skinner TE, Schmalbrock P, Robitaille PM (1994): Proton magnetic resonance spectroscopy of the hippocampal formation in schizophrenia: A pilot study. Br J Psychiatry 165:481-485

Pettigrew JW, Keshavan MS, Panchalingam K, Strychor S, Kapla DB, Tretta MG, Allen M (1991): Alterations in brain high-energy phosphate and membrane phospholipid metabolism in first-episode, drug-naive schizophrenics. A pilot study of the dorsal prefrontal cortex by in vivo phosphorus 31 nuclear magnetic resonance spectroscopy. Arch Gen Psychiatry 48(6):563-568

Renshaw PF, Yurgelun-Todd DA, Tohen MSG, Cohen BM 
(1995): Temporal lobe proton magnetic resonance spectroscopy of patients with first-episode psychosis. Am J Psychiatry 152:444-446

Roberts AC, De Salvia MA, Wilkinson LS, Collins P, Muir JL, Everitt BJ, Robbins TW (1994): 6-hydroxydopamine lesions of the prefrontal cortex in monkeys enhance performance on an analog of the Wisconsin Card Sort Test: Possible interactions with subcortical dopamine. J Neurosci 14:2531-2544

Rubin Y, LaPlaca MC, Smith DH, Thibault LE, Lenkinski RE (1995): The effect of N-acetyl-aspartate on the intracellular calcium concentration in NTera2-neurons. Neurosci Lett 198:209-212

Saunders RC, Kolachana B, Bachevalier J, Weinberger DR (1998): Neonatal lesions of the medial temporal lobe disrupt prefrontal cortical regulation of striatal dopamine. Nature 393:169-171

Selemon LD, Rajkowska G, Goldman-Rakic PS (1995): Abnormally high neuronal density in the schizophrenic cortex. A morphometric analysis of prefrontal area 9 and occipital area 17. Arch Gen Psychiatry 52:805-818

Shim SS, Bunney BS, Shi WX (1996): Effects of lesions in the medial prefrontal cortex on the activity of midbrain dopamine neurons. Neuropsychopharmacology 15: 437-441

Stanley JA, Williamson PC, Drost DJ, Rylett RJ, Carr TJ, Malla A, Thompson RT (1996): An in vivo proton magnetic resonance spectroscopy study of schizophrenia patients. Schizophr Bull 22:597-609

Svensson TH, Tung CS (1989): Local cooling of prefrontal cortex induces pacemaker-like firing of dopamine neurons in rat ventral tegmental area in vivo. Acta Physiol Scand 136:135-136

Urenjak J, Williams SR, Gadian DG, Noble M (1993): Proton nuclear magnetic resonance spectroscopy unambiguously identifies different neural cell types. J Neurosci 13:981-989

Weinberger DR (1987): Implications of normal brain development for the pathogenesis of schizophrenia. Arch Gen Psychiatry 44:660-669

Weinberger DR (1999): Cell Biology of the Hippocampal Formation in Schizophrenia. Biol Psychiatry 45:395-402

Weinberger DR, Berman KF, Zec, RF (1986): Physiological dysfunction of dorsolateral prefrontal cortex in schizophrenia. I. Regional cerebral blood flow (rCBF) evidence. Arch Gen Psychiatry 43:114-125 